Revista de Antropología Social

ISSN: 1131-558X

https://dx.doi.org/10.5209/raso.65622

\title{
El Mira antropólogo: el oficio de mirar y escribir
}

Joan Francesc Mira. 2018. El cercle màgic. Assaigs sobre cultures, pobles i nacions (1973-2008). (Beatriz Santamarina y Teresa Vicente, Eds.). València: Institució Alfons El Magnànim, Centre Valencià d'Estudis i d'Investigació.

Existen muchos Miras: el humanista, el catedrático de griego, el intelectual comprometido con su territorio, el profesor, el escritor, el antropólogo -y por ende también el etnógrafo-, y ¿por qué no?, también el conversador y el bromista. Viendo su apabullante vida no queda más remedio que reconocer, como dicen las editoras, que Joan Francesc Mira es un impresentable. Su recorrido profesional y académico es extraordinario, tanto en la academia como en distintas instituciones. Su obra da vértigo, ya sea en el ámbito de la antropología o de la literatura. Su repertorio de premios, nacionales e internacionales, es asombroso. Entre todas estas prolíficas facetas este volumen se centra en la de antropólogo, aunque las otras no dejan de emerger aquí y allá. Y con este objetivo, el de dar cuenta del Mira antropólogo, este compendio reúne veinticinco publicaciones del autor en una obra que se convierte en un texto indispensable para la antropología valenciana y española.

Pocos discreparán a la hora de otorgar el título de primer antropólogo del País Valenciano a Joan Francesc Mira, un autor que jugó un papel fundamental en los primeros pasos de esta diciplina no solo en el contexto valenciano, sino también en el conjunto del Estado Español. Sin embargo, era una tarea pendiente contar con un volumen que diera cuenta de la amplitud y profundidad de su producción antropológica. Una obra necesaria que se convierte en el reflejo de una antropología hecha desde, sobre y para el País Valenciano, sin que esto implique que pierda un ápice de interés para la lectora de fuera de este contexto. Un trabajo que se mueve con lucidez entre el ethnos y el anthropos; entre descripciones etnográficas llenas de sutileza, perspicacia y belleza, por un lado, y cuidadas reflexiones teóricas sobre aquello que nos atraviesa como humanos, por otro. A través de los diferentes textos, Joan Francesc Mira demuestra contar con las dos grandes virtudes que necesita toda buena antropóloga: la habilidad de observar y describir la complejidad de las realidades más cercanas y cotidianas; y, al mismo tiempo, la capacidad de ponerlas a conversar de manera sencilla con las principales teorías antropológicas y las grandes cuestiones de la humanidad. Como él mismo dice, la antropología "ha d'aconseguir que semble fácil allò que en realitat és molt difícil" (Mira, 2018: 13). Poder contar con una antropología clásica de estas características arraigada en el País Valenciano -y escrita en un perfecto valenciano- es un auténtico regalo que le debemos a Mira y que queda recogida en este libro.

Además, este compendio es parte de un proyecto de investigación más amplio que nos invita a descubrir al Mira antropólogo más allá de sus textos. Un proyecto encargado por el Museu Valencià d'Etnologia a la Universitat de València con el objetivo de dar a conocer la labor antropológica de Joan Francesc Mira. Tarea desarrollada 
por Beatriz Santamarina y Teresa Vicente, quienes se han embarcado con cariño en un apasionante viaje por los papeles y los recuerdos de un Joan que señalan como siempre amable y entrañable. Él las esperaba -como ellas dicen-con las puertas y los cajones abiertos y este libro es un reflejo de ello. Las imágenes del inventario de materiales de trabajo que se exponen nos trasladan automáticamente a un tiempo en el que el oficio de mirar y escribir se llevaba a cabo de manera -al menos en lo que a la materialidad se refiere- muy diferente. Mapas, tablas y gráficos hechos a mano con absoluta precisión, preciosas cartas de parentesco, prolijos extractos de diario de campo o hermosas fotos que se convierten en testigos de una antropología clásica hecha a partir de laboriosas y artesanales etnografías.

Uno de los resultados del proyecto es este libro, una selección acordada con el autor de veinticinco de sus textos de corte antropológico, diecinueve en valenciano y seis en castellano, respetando el idioma original en que fueron publicados. Un compendio que abarca un amplio periodo, entre 1973 y 2008, y que da cuenta de la rica trayectoria antropológica de Mira: desde sus primeros estudios etnográficos en la Tinença de Benifassà y su interés inicial por las transformaciones de la sociedad rural valenciana, hasta debates plenamente vigentes como el nacionalismo catalán o las migraciones, pasando por temas clásicos como pueden ser la cultura popular, el territorio o la identidad. Una diversidad de publicaciones que nos hablan de todos esos Miras con los que abríamos este texto y que las editoras ordenan en cuatro bloques temáticos.

El primero recoge cuatro textos en los que se abordan temas como cultura, cultura popular, simbolismo, tiempo, territorio o nación. A través de estos trabajos descubrimos la capacidad de Mira de definir con sencillez y claridad conceptos clásicos que han implicado -y siguen implicando- largos debates en la disciplina. El autor se declara incómodo con la imprecisión de algunos de los conceptos básicos de la antropología y se ocupa con lucidez de definirlos. En el más puro sentido de definir, como él dice, de ponerles límites, de aterrizarlos vinculándolos a ejemplos arraigados y cotidianos, de acotarlos lo máximo posible sin por ello sacrificar su complejidad. Y además sabe hacerlo de manera llana y amena, de forma que resulten comprensibles para cualquier lectora sin por ello traicionar la densidad de sus significados. Una habilidad que se agradece mucho en una disciplina donde por desgracia no siempre es habitual.

En este primera parte nos adentramos en ese cercle màgic que da nombre al libro. La sugerente idea de círculo mágico le permite tirar del hilo que hace que cosas como la cultura, el tiempo o las fronteras se vean investidas de una fuerza simbólica que las eleva a la categoría de fetiches dignos de las más intensas idolatrías, lo que los acaba por convertir al fin y al cabo en herramientas del y para el poder. Mira utiliza conocidas categorías de la antropología clásica, como son ídolo, tribu, brujería o magia, y las aplica con ingenio e ironía a nuestra propia sociedad. Esto le permite entender que la propia cultura -en su sentido humanista- se ha convertido en una especie de mito, en un sistema idolátrico, con fetiches consagrados, con objetos totémicos y rituales singulares asociados, con un reconocimiento reverencial a quienes la practican, e incluso con un orden institucional que administra la conservación y el culto. El objetivo último de todo este sistema idolátrico es unir a la comunidad de creyentes, consolidar la cohesión y confirmar de este modo el poder. Quienes detentan el poder invisten de magia a cosas como los museos, los calendarios o los mapas y los convierten así en objetos sagrados. A su vez, todas estas cosas convertidas en 
fetiches e ídolos de la tribu, que es la sociedad contemporánea, confirman su posición de poder. Y así se cierra el círculo mágico.

Lo anterior implica que la cultura ha devenido la religión de nuestro tiempo, lo que nos devuelve una imagen clara de nuestra sociedad que evidencia que somos tan fetichistas como esas tribus salvajes de la antropología clásica. De este modo, a lo largo de estos textos Mira explica de manera magistral uno de los grandes aprendizajes de la antropología: la cultura popular, la concepción del tiempo, el territorio nacional o las fronteras estatales no son cosas neutrales. Por el contrario, son productos culturales que solo podemos comenzar a entender cuando nos fijamos en las operaciones simbólicas que las vinculan con el poder. Así, quien domina el orden simbólico que constituyen todos esos elementos controla también la conciencia colectiva y el orden político. En sus propias palabras: "quien controla el contenido y significado de los símbolos, quien regula su difusión y aprendizaje, controlará también la «conciencia» resultante" (Mira, 2018: 78).

En continuidad con estos primeros textos se abre un segundo bloque donde estas categorías toman textura en contextos y tiempos particulares. A lo largo de seis textos aborda cuestiones como el tópico de la cultura mediterránea, la influencia de la Grecia clásica en la Grecia rural actual, el análisis de la Vila de Boixar medieval a través de textos jurídicos de la época, el paisaje agrario valenciano como reflejo de una forma particular de entender la relación con la tierra, las fiestas de toros en comarcas del norte valenciano como manifestación de valores sociales y de conflictos internos, o la rápida transformación de las sociedades campesinas tradicionales como resultado de la expansión generalizada de la sociedad industrial. A través de esta serie de textos que abordan temáticas y contextos tan dispares se evidencia la enorme habilidad de Mira para saber leer complejos entramados de valores culturales en cosas tan aparentemente sencillas como son el reparto de la carne al final de las fiestas de bous al carrer, las regulaciones medievales de los recursos colectivos en una aldea, o la perfección de los campos agrícolas de l'Horta de Valencia, por citar algunos ejemplos. No solo eso, sino que además queda patente la sensibilidad estética de Mira y su capacidad para ver y reflejar la belleza de todo aquello que etnografiaba.

El tercer bloque se compone de nueve textos cuyo hilo conductor son el nacionalismo, la identidad y el territorio. A través de estos trabajos vamos descubriendo uno de los principales ámbitos de investigación, reflexión y activismo de Joan Francesc Mira: el nacionalismo y la identidad nacional valenciana. De este modo, Mira constata que la nación se ha expandido hasta convertirse en una condición identitaria prácticamente universal y que nada hace pensar que vayamos a dejar de vivir, al menos próximamente, en un mundo de naciones. A partir de ahí, reflexiona sobre las diversas cuestiones que pueden dar forma a lo que llamamos identidades nacionales: unos mitos y una tradición histórica tomada por cierta, una lengua considerada propia, un territorio delimitado, una etnicidad diferenciada, fiestas y rituales compartidos, modos distintivos de organización social y, cómo no, manipulaciones simbólicas de toda clase. Las piezas de un rompecabezas imposible que, si todo va bien y por lo general gracias a la mediación de un Estado, pueden llegar a dar forma a un entramado más o menos coherente de representaciones comunes y, a su vez, a una conciencia colectiva de pertenencia. En resumidas cuentas y como diría él mismo, todas esas cosas que nos sirven para pensarnos y decirnos, y que, por descontado, tienen más que ver con los conflictos por el poder que con lo que en verdad somos o dejamos de ser. 
Todas estas deliberaciones teóricas toman tierra en las reflexiones que realiza Mira en torno al Estado Español, els Països Catalans y el País Valencià. Distintos textos le permiten abordar el proceso histórico de constitución del Estado Español y su relación problemática con las otras nacionalidades. Para Mira, el pueblo valenciano ha sido condicionado a verse como parte incondicional de la nación castellanoespañola y ha perdido la capacidad de identificarse con un entramado de representaciones que se pueda considerar propio y diferencial. Ha quedado atrapado entre dos lenguas, dos culturas, un conjunto disperso de símbolos carente de toda cohesión y una división territorial desintegradora. Frente a esta realidad, Mira toma partido y defiende un País Valenciano que empezar a construir a partir de aquello realmente compartido: una historia y un territorio propios. Un proyecto de identidad nacional que Mira, como buen antropólogo, sabe atravesado por invenciones, esencialismos y manipulaciones de símbolos. Exactamente igual que cualquier otro nacionalismo.

El último bloque es dedicado a otra de sus pasiones: la literatura. A través de estos últimos seis textos se abordan diferentes reflexiones sobre la antropología y la literatura como dos maneras de observar y exponer la realidad. Dos maneras que Mira, buen conocedor de ambas y consciente de sus diferencias, nos muestra como más similares de lo que cabría pensar en un principio. Desde ahí, nos invita a practicar una antropología que se parezca más a la literatura. Una antropología cálida y encarnada, cercana a la dimensión subjetiva y a la implicación personal, capaz de centrarse en "lo «incoativo», lo que se insinúa, lo que empieza y no acaba, lo que no se expresa de manera frontal y directa y unívoca: una mirada a la «oscuridad al fondo de la escalera... que está en el centro de la experiencia humana»" (Mira, 2018: 336).

A lo largo de estos cuatro bloques y veinticinco textos descubrimos a un antropólogo brillante, que muestra en cada uno de sus textos el dominio teórico de la disciplina, el compromiso político con su territorio, el cariño por sus lugares y el amor por esta extraña profesión. El resultado es que leer a Mira es un placer. Es un autor que nos emociona con su escritura sencilla y cercana, que nos ilustra con su dominio de los clásicos, que nos transporta a otros mundos con sus cuidadosas descripciones etnográficas, que nos engancha con sus argumentaciones y nos acompaña a dialogar con las grandes teorías de la disciplina, que nos divierte con su ironía y sentido del humor, que nos invita a seguir pensando al huir de conclusiones cerradas y dejar siempre la puerta abierta a lo irresuelto, a lo ambiguo, a lo paradójico, a nuevas preguntas. En resumen, un autor que nos deja siempre con ganas de más. De más antropología y de más Mira.

De entre todas sus virtudes me gustaría cerrar estas líneas resaltando dos. Por un lado, su capacidad de no perder nunca de vista el poder. "Pensem en el poder, per tant, perquè aquesta és sempre la qüestió i la mare de tots els ous i de totes les batalles" (Mira, 2018: 225), nos recuerda. Ya sea para entender por qué el mundo se divide en naciones, por qué determinadas prácticas se consideran cultura popular mientras que otras no o, pongamos por caso, por qué la foto del colegio debía hacerse con el mapa de España al fondo. Sea para lo que sea, Mira piensa siempre en el poder y al hacerlo nos va desvelando esos círculos mágicos que están en marcha en cada ámbito de la vida social, hasta en donde menos nos esperábamos.

Por último, la otra cuestión que quería subrayar antes de acabar es la enorme capacidad de Joan Francesc Mira para dudar de todo. De este modo, todos los trabajos que reúne este volumen son la prueba de su habilidad para cuestionarse sobre las cosas más naturalizadas e interrogarse incluso por aquello que se muestra más evi- 
dente. Iniciaba este texto señalando que para Mira este oficio de mirar y escribir al que nos dedicamos las antropólogas consiste sobre todo en hacer que parezca fácil lo difícil. Pero él hace algo más que eso. Consigue que lo evidente se vuelva fascinante y logra contagiarnos de esa ilusión por extrañarnos ante la vida. De alguna manera, todo este libro se convierte en un eco de un viejo alegato de la antropología: dejarnos sorprender por todas esas cosas que llegamos a hacer y creer las personas. Como él mismo diría: "Quan hom hi pensa amb calma, resulten ben sorprenents les coses que arribem a creure" (Mira, 2018: 231).

Hernán Fioravanti Departamento de Sociología y Antropología Social. Universitat de València. hernan.fioravanti@uv.es 